Teigen, K. H. \& Kanten, A. B. (2019). Are random events expected to be small? Psychological Research. doi: 10.1007/s00426-019-01252-9

Fulltext available at https://rdcu.be/bSDLE

\title{
Are random events expected to be small?
}

\author{
Karl Halvor Teigen ${ }^{1}$ and Alf Børre Kanten ${ }^{2}$
}

\author{
${ }^{1}$ University of Oslo, Norway \\ ${ }^{2}$ Bjørknes University College, Oslo, Norway
}

Correspondence to:

Karl Halvor Teigen

Department of Psychology

University of Oslo

Norway

e-mail: k.h.teigen@psykologi.uio.no

tel +4798014189 


\begin{abstract}
(246 words)
People's intuitions about mathematical and statistical concepts often include features that are not a part of the formal definitions. We argue that randomness and related concepts (events happening "accidentally", "coincidentally" or "by chance”) are typically assumed to occur in a context of small rather than large events. Five experiments were designed to test the hypothesis of an association between perceived randomness and size. In Experiment 1 and 2 statements describing small outcomes as due to chance were judged to be more natural and to make better sense than corresponding statements about large outcomes (or about small outcomes not due to chance). Experiment 3 showed that people imagine that stories about randomness in daily life should preferably start with small events, even when they eventually turn out to be consequential (e.g., stories about an apparently random meeting ending with marriage). Experiment 4 demonstrated that small changes in a graph of a random walk were seen as random, whereas large changes were perceived as potentially nonrandom. Finally, Experiment 5 showed that small animals are believed to display more random behavior than larger ones. This applied also to fictional creatures with nonsense names, where size was implicitly suggested by the names' phonetic qualities. Analogical instances can be found in the history of science, all the way back to Lucretius' doctrine of the tiny "swerves" of atoms. The pervasive association between smallness and randomness might be partly due to real world observations and partly to cognitive and motivational constraints.
\end{abstract}




\section{Are random events expected to be small?}

Most people want their world to be predictable and orderly, especially when it comes to the major events in life. Scientists are no exceptions. They hunt for regularities, and, like Einstein, shudder at the thought of God playing dice with the universe. Yet all of us encounter events that cannot be controlled or predicted and seem to happen "for no obvious reason". We speak in such cases of outcomes that seem to occur randomly, haphazardly, accidentally, or by chance.

Randomness can be formally defined in terms of process, by which all outcome elements have the same probability of occurring and are sequentially independent, leading to irregular, uncontrollable, unpredictable and incompressible (complex) patterns, as with lotteries or a string of tosses of a coin (e.g., Nickerson, 2002, Falk \& Konold, 1997). But not all such patterns will be perceived from a subjective point of view as equally random. People expect, for instance, that a random binary sequence should contain an approximate equal number of elements of each kind, and be characterized by frequent alternations (Scholl \& Greifeneder, 2011; Yu, Gunn, Osherson \& Zhao, 2018). This would make each part a "representative" sample of its parent population, as well as reflecting salient features of the processes by which it is generated (Kahneman \& Tversky, 1972; Teigen 2017).

Randomness is typically "negatively" defined to denote events that are not intended and cannot be predicted or controlled. Such events have alternatively been said to happen fortuitously, accidentally, incidentally, by chance or "by sheer luck". Although these terms may apply to slightly different contexts and highlight different aspects of an irregular happening (for example, "incidental" suggests a non-intended side-effect, and "luck" is mainly used about events that have a valenced - positive or negative - outcome), they are in many cases used interchangeably. In a discussion of the distinction between "random" and 
"by chance", Eagle (2018) concludes that in ordinary language (and sometimes in textbooks) people use these two terms as synonyms.

Intuitive notions of randomness can be expected to have connotations that go beyond the formal definitions. The present research focuses on intuitions about the role of event magnitude. We surmise that people feel it is easier and more acceptable to admit the presence of random processes when it comes to small-scale than to large-scale events. They might think that mosquitos move more erratically than elephants; fights in kindergarten might arise by chance, but armed conflicts between nations are more rarely considered random. A survey about the perceived origins of The Great War (WW1) showed "by chance" to be considered the least important of 14 potential reasons for its outbreak (Bouchat et al., in press).

An association between randomness and "smallness" can lead to over-attributions as well as under-attributions to chance. A small and apparently trivial mix-up of directions (like turning right instead of left) or a memory lapse could be dismissed as a "random" error and thus preclude a further investigation of its causes, but might, however, be an early symptom of dementia (Hagberg \& Gustafson, 1985). At the other extreme, large and important political and historical events are easy targets for believers in conspiracy theories who reject the notion of coincidence and chance (Brotherton \& French, 2014; Douglas, Sutton \& Cichocka, 2017). There may be good reasons for examining large events more closely than small ones, but attributions to randomness should, in principle, be independent of magnitude of event.

\section{Lay conceptions of randomness}

Perceptions of randomness have in psychology been studied largely in a context of composite events, particularly sequences of binary stochastic outcomes like tosses of a coin or drawings from an urn (for reviews, see Bar-Hillel \& Wagenaar, 1991; Nickerson, 2002;

Oskarsson, Van Boven, McClelland \& Hastie, 2009). These studies have shown that randomness is subjectively conceived as the absence of any discernible order, or pattern. The 
"events" observed in such studies are, by definition, of equal magnitude, preventing any inferences to be drawn about the role of smallness. Yet the constituent elements of sequences used to exemplify randomness are typically small and easily produced, like coin flips and throws of dice. Randomness is rarely illustrated by more momentous events, like sentences in court or the outcomes of presidential elections. It may be no coincidence (sic) that the first studies of visually presented random arrangements used displays of small dots symbolizing raindrops (Piaget \& Inhelder, 1971/1951; Gemelli \& Alberoni, 1961).

But people speak in daily life less about random series than about singular "chance" events, like chance encounters, serendipitous findings, random observations, slips of attention, and strokes of good or bad luck, events that cannot be attributed to a single dominant cause, intention or a plan, and hence must be considered (partly or entirely) random. Such events may have been downplayed by psychologists (Bandura, 1982) and social scientists, who are keen at discovering regularities and behaviors they can predict (Krantz, 1998; Sunstein, 2015). Yet they play an important role in lay people's autobiographical stories of their life and their careers (Blanco \& Golic, 2015; Krumbolz, 2009), and form an integral part of measures of attribution style, specifically representing external locus of control (Rotter, 1966; Nowicki \& Strickland, 1973).

Previous research on people's perception of chance events has revealed several characteristics that overlaps with those discussed in formal accounts of randomness, but in a more loose and metaphorical sense. Some of these connotations may have been acquired early in life through their links to more naïve or primitive conceptual resources (Piaget \& Inhelder, 1971/1951; Pratt \& Noss, 2002). Pratt (1998) interviewed 10-11 years old children engaged in computerized spinner and dice games. Their remarks on randomness were not far away from those one could have expected from adults, and could be classified into four overlapping categories: Unpredictability, unsteerability (lack of control), irregularity, and fairness. 
Unpredictability and irregularity were also the two main arguments for perceived randomness in sequential and two-dimensional arrays by 14 and 17 years olds, interviewed by Batanero and Serrano (1999). Jolfaee, Zazkis, and Sinclair (2014) asked college students to produce their own illustrative examples of random phenomena, and found that only a minority of their examples (about 15\%) had mathematical content, despite the fact that participants were prospective mathematics teachers and the data were collected in a mathematics-related course. More extensive interviews revealed the same criteria for randomness as in Pratt's study, except for fairness. Additional features mentioned were variability, lack of plans and structure, ignorance, typicality, and relative rarity. Low probability, or rarity, was also suggested by Shanahan and Porfeli (2006) as one of four potential criteria for perceived randomness, but without substantiating evidence. Many chance events, especially coincidences, reported in the literature, are described as unique and rare. In contrast, some very rare outcomes may arouse suspicions that they are not due to chance (Johansen \& Osman, 2015), but become more likely if one adopts an initially unlikely theory, for instance about conspiracies or paranormal phenomena (Griffiths \& Tenenbaum, 2007). Teigen and Keren (2019) asked people to rate the degree of randomness involved in various uncertain events, ranging from lotteries to exam grades and football matches, and found that the less likely of several comparable events were generally regarded as more random. This follows perhaps most directly from the concept of (un)predictability, as it is difficult to foresee when a low probability event will occur (although on a given trial, we may confidently predict that it will not occur). These studies did not involve manipulations or measures of perceived event magnitude; participants in these studies were asked to rate the randomness of likely and unlikely outcomes, but not their size.

\section{Smallness as a characteristic of chance}


There is nothing in the formal definitions of randomness that mentions magnitude of event as a defining feature. Dice can be of any size, and coin toss with a silver dollar is as random as a nickel. Yet on a more informal level it might be easier to associate chance with small objects, minor events, and unimportant consequences than with large ones. Or, in terms of Kahneman and Tversky's (1972) representativeness heuristic, we may think that smallness is a "representative" feature of randomness, making small random outcomes more likely than large ones.

The notion of a chance events as small can gain support from several observations, some being of an empirical nature, while others may be rooted in folk theories of explanations.

1. According to a widespread "mechanism" view of causality (Ahn \& Kalish, 2000), events have properties that bring forth certain effects by necessity. Deterministic beliefs suggest that most happenings in the external world are governed by "laws of nature", and thus in principle predictable. Similarly, most acts of sentient agents (animals and people) are explained as a result of motives and intentions, by default (Rosset, 2008). Thus, unpredictable events in nature and unintended acts may be regarded as exceptions and a factor of minor importance. If the main events in nature or in life are explainable, only details can be left to chance. Related to this notion is the popular belief, originally proposed by John Stuart Mill (1856), about a correspondence between causes and effects, implying that unimportant causes are expected to give rise mainly to unimportant (small) effects. In other words, people may regard small events as more typical or "representative" of those that happen for no apparent reason than of those that can be deterministically explained.

2. Observations of stochastic phenomena confirm that chance variations appear more prominent at a local than at a global level. The means of a large number of events are more stable than small sample means (according to the law of large numbers). Means are in turn 
more stable than the outcomes of individual events; thus a myopic view of individual events may appear chaotic, even when they together make up a more general, lawful trend. Besides, the distributions of individual observations around a more stable mean will show more deviations that are small than large. If we regard such deviations as happening by chance (random deviations), small chance events will outnumber the large ones. Thus, one can predict that in a binomial or normal distribution small deviations are more likely to occur than large ones. An over-generalization of this relationship might lead to the inverse (but not equivalent) prediction, namely that small events are more likely to be due to chance.

3. Given the limitations of our observational powers, it may be easier to notice large causes than small ones. They may also be more memorable. The philosopher and mathematician Henri Poincaré offered the following description of what, in his view, defined a random event: "A very slight cause, which escapes us, determines a considerable effect which we cannot help seeing, then we say this effect is due to chance" (1963, p. 141). Conversely, the non-chance determinants of large effects may be more prominent and readily observable than those responsible for small ones. The causes of a flood may be visible for the naked eye, but why one raindrop hits this particular cobblestone and not the adjacent one, is much less obvious. Thus, we resort to randomness to explain the drop, but not the torrent.

4. In addition, attempts to explain why details fall out one way and not the other may not be worth the effort. With two lifts in the hotel corridor, why should I bother to explain why I chose to board the left one or the right one, if both will bring me down to breakfast. It is enough to say that randomly, or for no particular reason, I chose this time the left one. It would be more imperative to figure out why this choice was made the morning it was stuck between two floors and made me miss my breakfast altogether. The need for explanation increases proportionally with the event's magnitude and importance, as well as with degree of novelty, deviance, and surprise (Bruckmüller, Hegarty, Teigen, Böhm, \& Luminet, 2017). In 
all these cases attributions to randomness are not satisfactory. In line with this, people find it easier to use a randomizer (e.g., a coin) to settle an unimportant dispute than to decide whose life to save (Keren \& Teigen, 2010).

5. It is well known from the literature about the physical metaphors of abstract concepts and also from studies of embodiment that largeness and weight are associated with potency (Osgood, Suci \& Tannenbaum, 1967) and importance (Barsalou, 2008; Jostmann, Lakens \& Schubert, 2009). In line with this, we might suspect that the imagined "smallness" of random events, could alternatively be described in terms of lightness. People know, from an early age, that light objects are more easily moved around and knocked over by chance or accident than large and heavy ones, suggesting a close correspondence between randomness and lightness. For similar reasons, they may also think that heavy organisms are less disposed to show random variability in how they move around, which may appear more natural for lighter organisms whose movements appear less constrained by inertia.

An association between randomness and smallness may accordingly be derived both from lay theories about the real world (determinism) and observations of external variability, with small deviations occurring more frequently than large. It may in addition be fueled by our ability and motivation to look for and discover presumptive causes, and finally by generalizing from subjective experiences with incidental movements of light vs. heavy objects.

For these (and perhaps other) reasons we expect people to intuitively assume that random events and processes are "small" rather than "large". Even if event magnitude doesn't form a part of the most common definitions of randomness (for an overview, see Nickerson, 2002), and is rarely mentioned in the literature of lay perceptions of chance, as reviewed above, beliefs about chance effects as rather insignificant and small are not without a factual basis. Like other judgmental principles (e.g., those suggested by "the heuristics and biases 
approach”, Kahneman, Slovic \& Tversky, 1982; Gilovich, Griffin \& Kahneman, 2000), they may originate in assumed or observed regularities that subsequently are over-extended to situations to which they do not necessarily apply. If randomness in people's mind connotes smallness, minor events may appear more random than larger ones, and conversely - random as opposed to non-random events might more easily bring to mind processes and mechanisms of small-scale magnitudes.

The present studies were not designed to test competing explanations about the origins of a link between randomness and event magnitude. Their purpose was more basic, namely to demonstrate the existence and generality of this link in people's "lay theory" of randomness. Do people think randomness (i.e., happenings they claim occur by chance) is more characteristic of small than large events? Do they, in general, find it more natural to describe local and insignificant outcomes as being "due to chance", and will they think that the immediate consequences of random events will be small rather than large?

In five experiments, we investigated whether an association between "smallness" and "randomness" generalizes to situations where the nature and amount of variability is not known, or where the causal determinants are not discussed. The first two studies asked people to evaluate statements about large or small outcomes that are explicitly said to be (or not to be) due to chance. We expected that people would feel that statements about small events made more sense, and sounded more natural, than corresponding statements about events of a larger magnitude. In the third study we ask participants whether they think the stories people tell about chance in their life (even those that turn out to be consequential) are typically initiated by minor random occurrences. The fourth study displayed a random walk of a hypothetical stock price and participants were asked to mark changes they guessed were not random. We expected large changes to be perceived as potentially nonrandom, whereas small changes were assumed to be random. In the fifth study, we investigated (1) whether real and 
imaginary small (light) animals are assumed to move more randomly around than larger ones, and (2) whether amount of random behavior exhibited by an organism, informs judgments about its physical size.

\section{Experiment 1}

\section{Method}

Participants. We recruited 201 individuals from Amazon Mechanical Turk, who were randomly assigned to two versions of the same questionnaire. We excluded participants who either failed a simple attention check, did not respond to all depended measures, or omitted to provide their mTurk ID, resulting in a final sample of 102 women and 97 men $($ mean age $=$ 36.8). We used the same exclusion criteria for all subsequent mTurk-studies.

Questionnaires. All questionnaires contained 12 pairs of statements about events that were explicitly claimed to be due to (or not due to) chance. One statement in each pair described a comparatively small outcome and the other a much larger outcome, for instance "Bob accidentally made a small [huge] mistake", or "It was no accident that the company's revenue had increased by 5\% [50\%]" (this item was reverse scored). Participants were asked to indicate which of the two statements that made more sense and was felt to be more natural. To avoid associations limited to one specific term, the statements contained a variety of nearsynonyms to randomness, namely randomly, by chance, accidentally, incidentally and happened to (see Table 1). In addition, two parallel sets of statements were constructed employing different terms, so for instance "It was no accident" in the (a) version was changed to "This did not happen by chance" in version (b). The 12 statement pairs were presented to participants in random order.

\section{Results}

Answers were scored 1 or 0 for selecting "small" and "large" outcomes as due to chance, respectively. Mean sum scores of 12 items were 8.97 in the (a) version and 8.62 in the 
(b) version of the questionnaire, significantly higher than a neutral sum score of $6 ; t(98)=$ $17.64, p<.0001$ and $t(99)=13.64, p<.0001$ for one-sample t-tests in the two versions, respectively. Overall, "small” statements were selected as more natural in $73 \%$ of all responses.

\section{<Insert Table 1 about here>}

As the two versions of the questionnaire produced the same pattern of results, results from both versions were pooled. Overall percentages of participants preferring statements about small outcomes as due to chance for each item are displayed in Table 1. Only two items, Q9 and Q12, did not show a significant preference for small outcomes. These questions concerned small vs. large landslides and serious vs. inconsequential malfunctions. In these domains, large incidents typically attract more attentions than small ones, and might accordingly be discussed more often, even if small incidents occur more frequently, making both statements appear equally "natural".

Participants in this study were explicitly asked to compare small and large outcomes in a within-subjects design. Such designs will make people more aware of the independent variable (Kahneman, 2003; Kahneman \& Tversky, 1996) and may accordingly be more strongly influenced by it. The study also did not control for non-chance outcomes. Most of the statements (with exception of the three that were reverse scored) described outcomes that were produced "by accident", "by chance" or "randomly". To show an association between randomness and smallness one must also demonstrate that non-random outcomes can be described as larger. These requirements led to the design of Experiment 2

\section{Experiment 2}

In this experiment statements about small and large outcomes were presented to two different groups of participants in a between-subjects design. In each group participants were 
shown pairs of statements that either attributed the outcome in question to chance (accident, happenstance, or randomness), or asserted that such attributions were unlikely. Based on the presumed association between randomness and smallness, we expected that participants in a small outcome condition would be more inclined to favor chance attributions over non-chance attributions, compared to participants in a condition where outcomes were described as large.

\section{Method}

Participants. Two hundred and one MTurk workers were originally recruited as participants. After using the same exclusion criteria as above, our final sample consisted of 195 individuals (100 women and 95 men; mean age $=38.6$ ). Participants were randomly assigned to a "small" or a "large" condition.

Questionnaires. Within each condition, participants received a questionnaire with 8 pairs of statements, attributed to experts in various fields. Five of the pairs were about effects that were said to be either typically or not typically due to chance. For instance, in the Small condition, a psychologist says: "Throughout adulthood, small variations in life satisfaction are [A: rarely] [B: often] due to random occurrences". In the Large condition, the corresponding pair of statements described "large variations in life satisfaction" instead of small variations. In addition, the questionnaires included in both conditions three filler items, which described small or large causes having small or large effects, without mentioning chance (e.g., a journalist says: "A small mistake will have [A: an significant] [B: an insignificant] effect on the company's reputation"). We expected these items would show a similar response pattern as the items about chance, based on the lay belief that small causes have small effects (LeBoeuf \& Norton, 2012; Mill, 1856; Nisbett \& Ross, 1980).

Participants were asked in both conditions to rate which one of the two statement in each pair, A or B, that appeared more natural, or made more sense, on a five-point scale from 1: Definitely A, to 5: Definitely B. Prior to analyses, we reverse-coded some items so that the 
prediction was always that the scores should be lower in the "small condition" than in the "large condition". For the complete set of statements, see Table 2.

\section{Results}

Mean ratings (see Table 2) show that statements about outcomes being due to chance were consistently more strongly preferred in the Small condition than in the Large condition, for all five pairs of target statements. A mixed ANOVA with Item and Condition as the two factors yields $F(1,193)=13.416, p<.001$ for Condition. There was also a significant effect of item, $F(4,772)=18.749, p<.001$, but no significant interaction.

Also the ratings of the three "filler" items were answered differently in the Small and the Large conditions, $F(1,193)=12.472, p=.001$ for Condition, suggesting that it is more natural to attribute large effects to large than to small causes, as predicted by Mill's (1856) correspondence principle (see also Keren \& Teigen (2001) and Kupor \& Laurin (2019) on the correspondence between probabilities and expected magnitude of outcomes).

<Insert Table 2 about here>

\section{Experiment 3}

The previous experiment was based on the assumption that random events, being small, would generally have correspondingly small effects. We also expected, and found, a similar effect with filler items about events that were simply described as "small" with no mention made about their degree of randomness. But a number of anecdotal events described in the literature as illustrating chance (Bandura, 1982; Blanco \& Golic, 2015; Krantz, 1998; Shanahan \& Porfeli, 2006) had important consequences for those involved. Thus, we find it reasonable that many stories of randomness in life will not be restricted to events of minor importance, like choosing the door to the right or to the left, or being assigned to Condition 1 or 2 in an experiment. They would rather tell stories about memorable and remarkable 
happenings, like meeting their future partners by chance, or barely missing a plane that eventually crashed, even if such events are exceptional and happen rarely. But even in such stories the initiating event (the meeting, or the miss) might be conceived as minor, and at the time it happens, seems rather insignificant. To check this out, we asked participants in Experiment 3 about what kind of narratives people are inclined to tell when sharing their own stories about randomness in life. We expected them to think of stories that could be either consequential (to be interesting), or trivial, if they had nothing else to tell, but in both cases emerging from a rather modest set of circumstances. The correspondence principle of Mill predicts that large effects are believed to have large causes. We predict, in contrast, that if something consequential happens as a result of chance, the causes are still believed to be of a small magnitude.

\section{Method}

Participants. Participants were 95 psychology students (66 women, 25 men, 4 did not indicate sex; mean age $=22.6,3$ did not indicate their age) ) attending a class in social psychology at a Norwegian university.

Questionnaire. The questionnaire contained the following instructions (translated from Norwegian):

Some friends are talking about things that have happened to them in their lives. They start to talk about random events. Many of the stories dealt with how by pure chance, it sometimes happens...

1. large things that are not very consequential

2. large things that can be very consequential

3. small things that are not very consequential

4. small things that can be very consequential

Please select the statement you feel is the most appropriate in this setting. 
In line with the hypothesis of randomness as "small" we expected Statements 3 and 4 to be most frequently selected, and particularly that Statement 4 would be more often selected than Statement 2, pitting the assumption of chance as small against the correspondence

principle of large events as having large causes. For the relationship between Statement 3 and 4 we had no prediction (except that stories of the last kind would be quite frequent, given that people have a preference for recalling and sharing interesting stories).

After answering this question, participants were given the opportunity to provide an illustrative story, either (a) one from their own experience or (b) one made up for the occasion.

\section{Results}

As shown in Table 3, an overwhelming number of participants $(90.5 \%)$ selected stories about "small" things; but a story worth sharing should presumably be consequential rather than insignificant. Almost half of them (48.4\%) added an illustrative story, mostly from their own life. Both real and made up stories started typically with a small event, but fewer real-life stories were consequential than corresponding made-up events (significant with Fischer's exact test, $p=.036$ ). The most popular theme was chance encounters with a person who eventually became one's partner or a close friend (about one third of all stories). Other stories described negative events, from small mistakes to serious accidents; still others contained more neutral coincidental meetings.

<Insert Table 3 about here>

In sum, the results confirm that chance stories are expected to start with small things, but a majority will have significant implications, presumably to be memorable enough to qualify as a story. Thus, many of them were indistinguishable from good or bad luck stories (Pritchard \& Smith, 2004; Teigen, 1995; 2005). This applied particularly to made up stories, 
which most easily can be adapted to a story script, whereas illustrative chance events from real life were on the whole more trivial.

\section{Experiment 4}

A random series of numbers will sometimes be perceived as non-random, at least in part. For instance, it has been suggested that day-by-day variations in the market price of stocks are essentially unpredictable (despite brokers' claims to the contrary), and that the ups and downs can be indistinguishable from a "random walk", as illustrated by Figure 1 (Cootner, 1964; Fama, 1995; Malkiel, 2003). It is apparent from this figure that some changes will (randomly) go on for a longer time and hence become much larger than others. From the general hypothesis of random events as "small" we predict that people will consider major and enduring increases or decreases to be less random than smaller and more shortlived ones.

Large and small are relative concepts. In Figure 1, two changes (one downward and one upward) are clearly larger relative to the others, by indicating several consistent changes in the same direction. But all changes in the figure can also be made larger or smaller by changing unit size on the Y-axis. To this end, we reproduced the figure in two versions, one with expanded and one with reduced scale. In the expanded figure, unit size was about twice as large as in the reduced one. If perceived randomness is directly related to physical and/or perceptual size, changes in the large-scale figure should be judged less random than corresponding changes on the small-scale graph.

<Insert Figure 1 about here>

\section{Method}

Participants. For this study, we recruited 227 MTurk workers. After employing the previously described exclusion criteria, our final sample consisted of 211 individuals $(53.8 \%$ 
male, one did not indicate sex; mean age $=39$, one did not indicate age). They were randomly allocated to two conditions, receiving either a large-scale or a small-scale version of Figure 1. Procedure. All participants received the following three questions along with different versions of the same graph, one large scale (Condition 1) and one small scale (Condition 2), both based a graphical illustration of a random walk. Thus, both figures were of the same width, but differed in scale on the vertical dimension.

1. Imagine you are a financial analyst, observing the changes of a stock over a three months period. You wonder whether the changes are purely random or could rather be explained by the effects of specific causal factors. To this end, you concentrate on changes that may be non-chance.

Click on all sections of the graph where you would specifically look for the effects of non-chance factors (for longer time periods, click on adjacent sections).

By clicking with the cursor on the line, a light green rectangle appeared on the screen covering the selected line segment. This made it easy for participants to mark and see all changes they selected. For coding purposes, the changes in stock price were numbered from 1-44 from left to right, corresponding to the 44 unbroken line segments in the graph.

2. Next, they were shown the same graph with four changes already marked, and were told that the figure showed which sections of the graph another participant had marked as caused by non-chance factors. The marked segments were among the largest changes on the graph (no. 12, no. 18, no. 21 and no. 36). They were then asked: "How likely is it in your mind that the changes this person selected are indeed produced by non-chance factors?" To be rated on a scale from 1: Very unlikely to 7: Very likely.

3. Finally, participants were shown the graph with a different set of markings, which allegedly were produced by another participant in a version of this study where people were 
asked the opposite question, namely to mark sections of the graph they would not scrutinize too closely, as these changes most likely could be attributed to randomness. The sections marked contained mostly minor changes (segments 4, 6, 8-17, 22-35 and 39-44). They were then asked "How likely is it, in your mind, that the changes this person selected can indeed be attributed to randomness?" To be rated from 1: Very unlikely to 7: Very likely.

\section{Results}

Most participants (88.0\% in Condition 1 and $86.4 \%$ in Condition 2) marked one or more changes in the graph as potentially nonrandom. The median number of markings were in both conditions 4 , with a range from 0 to 27 markings in the small-scale condition, and 0 to 16 in the large-scale condition. An inspection of marked changes show that these included, without exception, the largest ones. The two largest changes were perceived as non-random by more than half of the participants, as shown in Figure 2. Changes of medium size (\#12, $\# 18$, \#38, \#7, and \#19) were judged as nonrandom by 20-30\%, whereas the remaining 37

(small) changes were only selected by an average of $8 \%$. These results strongly confirm our main hypothesis, namely that people will regard major and consistent changes in a random walk as nonrandom, whereas smaller, transient changes are viewed as more compatible with a random process -- the smaller, the more random.

\section{$<$ Insert Figure 2 about here>}

Our second hypothesis was not confirmed. A large-scale version of the graph did not increase the number of changes that were considered non-random, and the effect of relative magnitudes were in both conditions similar, as seen by comparing the blue and the red bars in Figure 2. If anything, the number of changes selected was slightly higher in Condition 1 . We must conclude that conceptual rather than perceptual magnitudes of change determined in this study which changes appeared random and which did not. 
In Part 2 participants received a graph with four large changes marked. A majority (about 70\%) of participants in both groups judged this selected set of outcome prices to be most likely not random. Mean likelihood ratings of non-randomness were 5.02 in Condition 1 and 4.94 in Condition 2, both of these means are significantly higher than the scale midpoint of 4.00, as indicated one-sample tests; $t(107)=7.28, p<.001$, and $t(102)=6.26, p<.001$ in Condition 1 and Condition 2, respectively. Again, we found no effect of condition. Large changes in the large-scale condition did not generate higher likelihood ratings than in the small-scale condition.

In Part 3 participants were shown marked subsets of minor changes in the same graph. These sets were considered more likely to be random than not random, with mean likelihood judgments of 4.67 (Condition 1) and 4.58 (Condition 2). Both means are significantly above the scale midpoint; $t(107)=3.98, p<.001$, and $t(102)=3.95, p<.001$ in the two conditions, respectively. These results demonstrate that most of the variation in stock prices presented to participants (actually 32 out of 44 changes) are seen as compatible with random variations, provided that the changes are minor relative to the others.

To sum up: The graph used in this study displayed a random walk, yet most participants saw parts of it - those that contained larger changes - as probably not random. Perceived randomness was within each condition inversely predictable by magnitude of change. We found, however, no between-condition effect. Changes in a large-scale graph were not seen as less random than those in a compressed graph with smaller units, despite being physically and visually bigger. What counts, at least in a context of repeated events that easily can be compared to each other, is relative rather than absolute size of change. Instead of asking which outcomes are more likely a result of chance, we ask in the next experiment which kind of origin will more likely produce random effects: small organisms or large ones? 


\section{Experiment 5a}

Do people attribute random activities more easily to objects or organisms that are small rather than large? An association between randomness and smallness may manifest itself not just through small impacts or small consequences on the surroundings, but in the belief that small systems are more capable and more likely to behave in an erratic fashion. In order to test this idea, we constructed a vignette, based on the claim (by cell biologists) that there could be a neural mechanism responsible for stochastic variability in animal behavior (Tervo et al., 2014), and asked non-experts to which extent they thought such behavior was present in organisms of different size. Experiment 5a featured common animals which vary in terms of average weight. Experiment $5 \mathrm{~b}$ made use of fictional creatures whose imagined size were suggested by made-up names (Davis, Morrow, \& Lupyan, 2019).

\section{Method}

Participants. Two hundred and two MTurk workers were initially recruited. After exclusions, the final sample contained 196 individuals (52.8\% female, one did not indicate sex; mean age $=37.9$, one failed to provide age) .

Questionnaires. All participants received the same basic vignette asking them to rate the degree of randomness involved in the behavior of 20 distinct animal species. As observable random behavior is dependent on manner of locomotion, they were divided into two categories, to be analyzed separately: (1) Ten winged creatures ( 2 insects and 8 birds) and (2) ten four-legged animals (all mammals). The selected animals were assumed to be familiar to most respondents, and of widely different size according to average weight estimates, obtained from Wikipedia and other sources. The first category ranged from mosquito $(2.5 \mathrm{mg})$ to swan $(10.3 \mathrm{~kg})$, and the second from house mouse $(42.5 \mathrm{~g})$ to Indian elephant $(3500 \mathrm{~kg})$. For a complete set of species and their estimated mean weights see the Appendix. 
The list of animals (with birds and animals mixed and presented in random order) was introduced as follows:

Biologists have recently discussed the ability of animals to vary their behavior by making unpredictable random movements. This could increase their chance of survival, for instance in escaping from predators, finding a mate, getting out of a trap, and learning by trial and error ${ }^{1}$. To date, such behaviors have been studied in several species, including the ones listed below. They have received scores according to how much of their daily behavior that can be classified as random (according to statistical criteria).

Part 1. Randomness estimates for each species were performed on five-point rating scales that highlighted either the amount of random behavior displayed, or the ability to produce such behavior, in two different conditions.

Condition 1 Amount. "We wonder whether people who are not experts on animal behavior can correctly judge which animals that show a lot or very little of such behavior". (To be rated from 1: Few random movements, to 5: Many random movements)

Condition 2. Ability. "We wonder whether people who are not experts on animal behavior can correctly judge the extent to which animals have the ability to produce random variations in their behavior." (Rated from 1: Low ability to produce random movements, to 5: High ability to produce random movements.)

Part 2. Participants' own reasons for ascribing randomness to the different animals were then examined by asking them to rate their agreement (from 1: totally disagree to 5 : totally agree) with the following statements:

\footnotetext{
${ }^{1}$ We included on purpose functions that did not consistently favor small or primitive animals. For instance behavioral flexibility (learning) and finding a mate "by chance" could be advantageous for species at all levels of the evolution.
} 
My judgments about random behavior among animals were partly based on my knowledge and impressions about....

1. These animals' movement patterns

2. Their size

3. Their intelligence

4. Their environment

5. Their food preferences (meat or plants)

6. Other (please specify)

Part 3. While the questions above were concerned with random behavior across different species, with no explicit mention made of size, the final question explicitly asked participants to express their opinion on the presumed randomness of small and large individuals within the same species. This would control for an effect of lay beliefs about specific species, for instance about animals belonging to a small species as less intelligent (and hence behaving less deliberately) or more vulnerable to predators. The same question was presented to participants in both conditions.

Within each species, which animals do you think perform more random movements?" Small animals / Large animals / No difference

\section{Results}

Mean estimated randomness for different species birds and animals indicates a trend for heavy animals in both categories to behave less random, consistent with our main hypothesis. This relationship appeared to be stronger for Condition 1: Amount of random behavior, than for Condition 2: ability to behave randomly. It also seemed more prominent within the group of heavy animals than within the group of light ones. For a detailed report see Figure 5 and 6 in the Appendix. 
<Insert Figure 3 about here>

To simplify analyses, the five smallest animals within each category were grouped as "small" and the five heaviest ones as "large". Mean randomness scores for winged and fourlegged animals are displayed in Figure 3, showing in both cases higher scores for small than large animals, and higher scores for random ability than random behaviors. There is also an interaction between these two factors, with size being a stronger predictor of amount of random movements than of the ability to produce such movements. A mixed model ANOVA for the left panel Figure 3 (birds and insects) shows a highly significant main effects of size $F(1,194)=80.170, p<.001, \eta_{\mathrm{p}}{ }^{2}=.292$, and of condition, $F(1,194)=11.720, p=.001, \eta_{\mathrm{p}}{ }^{2}=$ .057 , and also an interaction effect of size $*$ condition, $F(1,194)=13.633, p<.001, \eta_{\mathrm{p}}{ }^{2}=$ .066. A corresponding analysis of the four-legged animals (Figure 3, right panel), yields similar effects, with a main effect of size $F(1,194)=124.847, p<.001, \eta_{\mathrm{p}}{ }^{2}=.392$, and of condition, $F(1,194)=13.994, p<.001, \eta_{\mathrm{p}}^{2}=.067$, as well as an interaction $F(1,194)=$ $6.961, p=.009, \eta_{\mathrm{p}}^{2}=.035$

An overall mixed 2 x 5 ANOVA for rated explanations showed no effect of condition, $F(1,194)=0.0004, p=.98$, but a significant effect of explanations, $F(4,191)=60.69, p<$ .001 , with pattern of movement rated, overall, as most important $(M=3.98)$. Also size was acknowledged to play a role $(M=3.45)$, but not much more than intelligence $(M=3.37)$ and environment $(M=3.19)$. Food preferences were rated as least important $(M=2.20)$.

It is reasonable that participants' prior knowledge about the movement patterns of these animals are more important than their size. For instance, guinea pigs received relatively low randomness scores, despite their size, probably based on their docile nature as popular pets. However, the high similarity between the graphs displayed for birds and mammals indicates that the size-randomness correlation is general across modes of locomotion. 
Size can be expected to play a more decisive role when other factors are controlled for. For instance, the domestic cat received consistently a higher randomness score than the tiger, both belonging to feline family, but differing in size. The final question revealed that a large majority thought that smaller individuals behaved more randomly than larger individuals of the same species. As many as $74 \%$ said small animals were more random than large ones, against only $4.6 \%$ who thought that large specimens behaved most random, and $21.4 \%$ who stated that they did not differ.

\section{Experiment 5b}

This experiment was performed to test the size-randomness hypothesis for animals with which one has no prior knowledge or experience. Davis et al. (2019) demonstrated that nonsense names, like keex and horgous, make people imagine creatures with different characteristics, presumably due to "phonetic symbolism" (Sapir, 1929), the meanings associated with different letters, syllables and sounds. Davis and colleagues asked their participants to imagine how creatures with made-up names would look like and could be rated on several dimensions, including small-large, masculine-feminine, and spiky-round. Of their 12 nonsense creatures, we selected six with the most marked difference in rated size and had them judged for randomness. Additionally, participants were asked whether animals with many random movements were expected to be smaller or as larger than other animals of the same kind.

\section{Method}

Participants. We distributed an online survey to 219 MTurk workers. The final sample consisted of 209 individuals, after exclusions (52\% female, mean age $=37.6)$.

Questionnaires, Part 1. All participants were told (as in Experiment 5a) that biologists had studied the ability of animals to make unpredictable random movements. They have now discovered and named six new species of animals, which have received scores according to 
how much of their daily behavior that could be classified as random. Participants were then told:

On the following pages, you will be presented with the names of these species. Although these species probably will be unfamiliar to you, we are interested in whether the names they received can help you to judge which animals that show a lot or very little random behavior. Try to visualize how the animal might look like before you make each judgment.

The six species were selected from the list of 12 fictional creatures provided by Davis et al. (2019), and included the three "smallest" creatures, (Ackie, Keex and Flissil) and the three "largest" ones (Horgous, Bomburg, and Boodoma), based on the ratings displayed in their Figure 2. These names were presented in random order and rated on five-point scales from 1: "Few random movements" to 5: "Many random movements".

In Part 2, participants were allocated to two conditions. They were told that marine biologists have described a new species of eel, that differed from other eels by their movements, "which for the most part follow a highly unpredictable and apparently random trajectory" (Condition 1) or, " for the most part follow a highly predictable and apparently regular trajectory" (Condition 2)-

Which of these statements do you think is also true about this new species of eel:

1. They are much smaller than most other eels

2. They are much larger than most other eels

A similar question had been asked in Part 3 of Experiment 5a, where participants indicated whether they thought small or large individuals of the same species exhibited the most random behavior (one condition only). This time the question about size in Condition 1 could be compared to the parallel question in Condition 2 where individuals belonging to the new species of eels are reported to follow a more regular, nonrandom movement pattern. 


\section{Results}

An overall ANOVA showed significant differences in randomness across the six species, $F(5,204)=16.31, p<.001$. Mean ratings of separate animals ranged from Horgous $(M=2.61)$, who was believed to show few random movements, to Keex $(M=3.58)$, who was assumed to make many random movements. Combined randomness ratings for the three “small" animals yielded a score of $M=3.38(S D=0.68)$, against $M=2.90(S D=0.85)$ for the three "large" animals; $t(208)=5.71, \mathrm{p}<.001$, Cohen's $d=0.62$. These results show that imagined creatures whose names suggest smallness are believed to move more randomly around than those with names suggesting largeness. Observe that participants in the present experiment were not asked to give explicit magnitude judgments. Yet their randomness ratings corresponding to the magnitude ratings of Davis et al.'s (2019) participants, who belonged to a comparable sample of MTurk respondents.

In Part 2, we used randomness as an independent rather than dependent variable, asking whether eels that are moving randomly are smaller or larger than other eels. In line with our prediction, almost $90 \%$ believed that eels with more random movements were smaller than "normal" eels. For eels with more regular movements than other eels there was no clear majority opinion; they could be larger, or they could be smaller (Figure 4). The difference between the two conditions is significant, $\chi^{2}(1, N=209)=30.60, p<.001$. $<$ Insert Figure 4 about here>

\section{General discussion}

People's understanding of scientific and mathematical concepts often contains features that are not included in the formal definitions. The concept of randomness is no exception. Prior studies have shown that people think random patterns should be balanced, but otherwise as irregular as possible, characterized by short runs and frequent alternations, whereas 
singular random events are believed to have a low probability of occurrence (Teigen \& Keren, 2019). The present studies demonstrate that people also think that the prototypical random event is a small one, and as such, one that tends to have small immediate consequences. In the first two studies, participants judged statements about small random events as making better sense than corresponding statements about large events. In these statements, randomnessrelated terms (by chance, accidentally, it happens) were used interchangeably indicating a "family" of overlapping constructs with similar connotations. Study 3 indicated that even if the stories people tell about random events can have important long-term consequences, they are believed to start with minor happenings. Study 4 confirmed that large changes in stock prices following a "random walk", are suspected to be due to non-chance happenings, whereas small changes can be attributed to chance. The final study showed that people assume small animals to behave more randomly than large ones; this held also good for fictitious creatures whose largeness was not stated explicitly, but indirectly suggested by the phonetic qualities of their names.

The subjective "intuitions" about randomness as rare and small may jointly contribute to the belief that randomness is a factor of low importance for events in society and in nature and can only play an insignificant role in life. As a result, people (and social scientists) might neglect the role of chance in their own biographies or in shaping history at crucial points in time (Bandura, 1982; Krantz, 1998). Instead they will feel called upon to give important (large) events speculative causal explanations, whereas explanations in terms of randomness or accidental effects will be considered insufficient or downright improper. The term "accident" itself has been condemned for (falsely) suggesting that such events have no causes and could not have been foreseen or prevented (Langley, 1988; Loimer \& Guarneri, 1996). The British Medical Journal even made an editorial decision to ban the term accident from their journal pages for fear it might attenuate responsibility (Davis \& Pless, 2001). 
Smallness is by itself a relative and subjective concept, implying that a small event from one perspective (a dog not barking) can loom larger for an attentive observer than for a less astute mind (Sherlock Holmes versus inspector Gregory). Accordingly, it is attributed more easily to chance in the latter case than in the former. Magnitudes are also affected by distance, so it might be easier to attribute an event that happened years ago to chance than one that has just happened. Questionnaire and interview studies have demonstrated the impact of serendipitous events upon the career paths of various vocational groups ranging from nonprofessional workers (Salomone \& Slaney, 1981), to prominent academic women (Williams, Soeprapto, Like, Touradji, Hess, \& Hill, 1998). Such reports are based on memories of past events that may look smaller from a distance than at the time they happened. Perhaps the same events did not appear so random when they first occurred.

We listed in the introduction several observations that might contribute to a link between randomness and smallness. The present studies were not designed to identify and assess the relative importance of these (or other) sources. They indicate, however, overlapping support for several of them. Experiments 1-3 suggest that people entertain beliefs about the apparent "smallness" of a random cause and its immediate effects, in line with Mill's (1856) hypothesis of a correspondence between effects and their causes, as well as Poincaré's (1963) suggestion that we tend to talk about chance outcomes when causes are too small to be observable. Beliefs in randomness as antithetical to consistency were demonstrated in the random walk experiment (Experiment 4), and the proposed prevalence of random movements in light vs. heavy organisms was tested in Experiment 5. We did not introduce motivational determinants as an independent factor in any of the studies. In Experiment 2 several of the "large" effects were at the same time more positive (attractive) or negative (severe) than the smaller ones, so in this study largeness and motivational impact were confounded. A separate test of motivational concernedness could however be integrated in several of the other 
scenarios, for instance by attaching higher low vs higher values to the stock price in the random walk scenario. We would in this case expect a higher willingness to accept price fluctuations as random among traders who have invested only small amounts of money than among those whose entire fortune is at stake.

Beliefs in an association between randomness and size may be adaptive. A large persistent dip on the stock market could forebode a financial crisis and be more compatible with a real recession than a random swing. To heed a major change more than a minor one when clouds appear on the horizon can be compatible with rational Bayesian reasoning (Griffiths \& Tenenbaum, 2007).

Whatever the origin of this association might be, if small events are viewed as more "representative" outcomes of a random process than large ones, they can be used heuristically to support the notion that an effect is (or is not) random. Such use makes event magnitude an instance of the representativeness heuristic (Kahneman \& Tversky, 1972; Tversky \& Kahneman, 1982). We might furthermore expect that labeling a specific outcome "random" would make people not just expect it to be minor but also deem it insignificant and more worthless, making people underestimate the importance of a "random sample", or the impact of an observation that is made "by chance". From the hypothesis of a correspondence between effects and their causes, it is easy to assume that random processes are less consequential than those that are designed or intended. This need not always be the case in real life, as demonstrated by the so-called Butterfly effect in chaos theory (Oestreicher, 2007), cascade and domino-effects in the realm of natural disasters (e.g., Kadri, Birregah \& Châtelet, 2014), and by the role of "Black Swans" in shaping history (Taleb, 2007). Observe that even in these accounts there is a tendency to think that the accidental element starts out with something minor (like the flapping of a wing), which only gradually exerts a growing impact on a complex system, ending in momentous effects. Similarly, we have seen from the present 
studies (especially Experiment 3) that a good story about randomness begins with something small but can end in heaven or in hell.

This is not a new idea. To place it in perspective we feel it appropriate to conclude with a brief excursion in the history of science, where randomness makes it appearance on the scene as a minuscule, but crucial element.

\section{A postscript from the history of science}

Discussions of causality versus randomness have been a part of science throughout history. The first Greek atomists were determinists and denied the possibility of chance. As expressed by Leucippus: "Nothing happens at random (matên), but everything for a reason and by necessity" (Andrew, 2013). But there were dissenting voices. If the movement of atoms are simply determined by their past collisions, as claimed by Leucippus and Democritus, how come that they collide in the first place? Epicurus is reported to have solved this problem by suggesting that the elementary particles deviate, or "swerve" at unexpected, unpredictable times from their straight downwards paths, and as a result collide and start to form composite material bodies. The details of this doctrine are spelled out in Lucretius' monumental poem "On the nature of things", written around 60 BC. A copy of this work was found in 1517 in a German monastic library. Steven Greenblatt (2011) claims that the rediscovery of this book by the Renaissance scholar Poggio Braccholini was as important as the discoveries of Copernicus and Galilei for the emergence of a modern scientific worldview, with universal mechanistic principles replacing mysterious forces and the acts of God (or gods).

In the Epicurean/Lucretian scheme of things the random swerve is an essential ingredient, without which atoms would fall straight down through the void, "like drops of rain", and no development of structures would take place. To make his claim believable, Lucretius (2015) emphasized the smallness of these deviations: 
“Thus, I repeat, the atoms have to swerve a little

But only by the smallest possible degree, a tittle" (p. 67. Book II, verse 244).

The idea of randomness as applicable to small events has appeared and reappeared in many disguises through the history of science. Darwin's theory of evolution is a case in point. From Lucretius to Darwin there is admittedly a long stretch, but one similarity remains, namely that they both tried to explain the emergence of order and apparent intelligent structures in nature based on blind mechanistic principles. For Darwin, the evolution of species was explained by natural selection, or in his own words:

"I have called this principle, by which each slight variation, if useful, is preserved, by the term of Natural Selection" (Darwin, 1859, Chapter 3).

Not only is Darwin, in this quote, summoning variability as a basic precondition for evolution, without further explanation of the source of this variability, which may well be described as pure chance, or randomness (Johnson, 2015), but he is also indicating that the variations he alludes to are typically slight.

Modern versions of ontological randomness are found above all in quantum mechanics (Aaronson, 2013) and genetics (Ruvinsky, 2010). Observe again that randomness is in these contexts conceptualized as small-scale events at a microscopic or subatomic level, which individually and to begin with will have small effects, but at a longer range can determine the direction of development and produce observable and important consequences.

\section{A replication of Lucretius}

Must random swerves be small? Lucretius' age-old claim seems echoed by the intuitions of lay people in the present studies. As an even more direct attempt to "replicate" Lucretius, we gave 151 MTurk workers one random (genuine) or one nonrandom (fake) version of Lucretius' doctrine [fake doctrine in brackets]: 
Some ancient philosophers proposed more than two thousand years ago a theory that the world was composed of atoms, falling through the void. More complex bodies were a result of collisions between these atoms. For such collisions to occur, the atoms had to depart from their straight course and make unpredictable [predictable] sideways movements. One philosopher, Lucretius, claimed that these "swerves" (as he called them) were completely undetermined and random [determined and nonrandom].

Do you think he also imagined them as being small, medium, or large? Rated from 1: Very small, to 7: Very large.

Participants in both conditions rated swerves as small, with 1 (very small) as their modal answer. We are, after all, talking about minuscule particles in both conditions. Despite this potential "floor effect", mean scores were somewhat lower in the random than in the nonrandom condition; $M_{\text {random }}=2.57(S D=1.81)$ vs. $M_{\text {nonrandom }}=3.13(S D=2.05), t=1.81, p$ $=.073$, Cohen's $d=0.29$. Sixteen participants reported some familiarity with the theory of swerves (scoring 3 or 4 on a 1-4 rating scale for prior knowledge). When they were excluded, the difference is significant, $M_{\text {random }}=2.27(S D=1.56)$ vs. $M_{\text {nonrandom }}=2.88(S D=1.91), t=$ 2.04, $p=.043$, Cohen's $d=0.35$. Moreover, participants in the random condition were in better agreement with each other (lower variance), $F(149)=4.30, p=.04$, by Levene's test for the complete sample, and $F(133)=8.27, p=.005$ when those with prior knowledge are excluded. So Lucretius' idea of random swerves as tiny appears to be shared lay participants ignorant of his theory, even today.

\section{Compliance with Ethical Standards}

Funding: This study did not receive funding from external sources.

Conflict of interest: There is no conflict of interest. 
Ethical approval: All procedures performed in studies involving human participants were in accordance with the ethical standards of the institutional and/or national research committee and with the 1964 Helsinki declaration and its later amendments or comparable ethical standards.

\section{References}

Aaronson, S. (2014). Quantum computing since Democritus. Cambridge, UK: Cambridge University Press.

Ahn, W., \& Kalish, C. W. (2000). The role of mechanism beliefs in causal reasoning. In F. C. Keil \& R. A. Wilson (Eds.), Explanation and cognition (pp. 199-226). Cambridge, MA: MIT Press.

Andrew, G. (2013) Leucippus and Democritus on Like to Like and ou mallon. Apeiron, 46(4) 446-468. https://doi.org/10.1515/apeiron-2013-0021

Bandura, A. (1982). The psychology of chance encounters and life paths. American Psychologist, 37, 747- 755. doi: 10.1037/0003-066X.37.7.747

Bar Hillel, M., \& Wagenaar, W. A. (1991). The perception of randomness. Advances in Applied Mathematics, 12, 428-454. https://doi.org/10.1016/0196-8858(91)90029-I

Barsalou, L.W. (2008). Grounded cognition. Annual Review of Psychology, 59, 617-645. https://doi.org/10.1146/annurev.psych.59.103006.093639

Batanero, C., \& Serrano, A. (1999). The meaning of randomness for secondary school students. Journal for Research in Mathematics Education, 30(5), 558-567. doi: $10.2307 / 749774$

Blanco, M. R., \& Golik, M. N. (2015). Born under a lucky star? Latin American CEOs' perceptions about their own career development. The International Journal of Human Resource Management, 26(14), 1865-1888, DOI: 10.1080/09585192.2014.964285

Bouchat, A., Licata, L., Rosoux, V., Allesch, C. ... Klein, O. (2019). Greedy elites and poor lambs: How young Europeans remember the Great War. Journal of Social and Political Psychology, 7(1), 2-75. doi: 10.5964/jspp.v7i1.781

Brotherton, R., \& French, C. C. (2014). Belief in conspiracy theories and susceptibility to the conjunction fallacy. Applied Cognitive Psychology, 28, 238-248.

https://doi.org/10.1002/acp.2995

Bruckmüller, S., Hegarty, P., Teigen, K. H., Böhm, G. \& Luminet, O. (2017). When do past events require explanation? Insights from social psychology. Memory Studies, 10(3), 261-273. doi: $10.1177 / 1750698017701607$ 
Cootner, P. H. (1969). The random character of stock market prices. Cambridge, MA: M.I.T Press.

Darwin, C. (1859). On the origin of the species. London: John Murray.

Davis, C. P., Morrow, H. M., \& Lupyan, G. (2019). What does a horgous look like? Nonsense words elicit meaningful drawings. psyarxiv.com/uve7d/ Preprint doi: $10.31234 /$ osf.io/uve7d

Davis, R. M., \& Pless, B. (2001). Accidents are not unpredictable. British Medical Journal, 322, 1320-1321. https://doi.org/10.1136/bmj.322.7298.1320

Douglas, K. M., Sutton, R. M., \& Cichocka, A. (2017). The psychology of conspiracy theories. Current Directions in Psychological Science, 26(6), 538-542. doi:

$\underline{10.1177 / 0963721417718261}$

Eagle, A. (2018). Chance versus Randomness. In E. N. Zalta (ed.). The Stanford Encyclopedia of Philosophy. https://plato.stanford.edu/archives/spr2018/entries/chance-randomness/.

Falk, R., \& Konold, C. (1997). Making sense of randomness: Implicit encoding as a basis for judgment. Psychological Review, 104(2), 301-318.

Fama, E. F. (1995) Random walks in stock market prices. Financial Analysts Journal, 75-80. https://www.jstor.org/stable/4479810

Gemelli, A., \& Alberoni, F. (1961). Experimental studies of the concept of chance. The Journal of General Psychology, 65, 3-24.

Gilovich, T., Griffin, D., \& Kahneman, D. (2002). Heuristics and biases: The psychology of intuitive judgment. Cambridge, UK: Cambridge University Press.

Greenblatt, S. (2013). The swerve: How the world became modern. New York: Norton.

Griffiths, T. L., \& Tenenbaum, J. B. (2007). From mere coincidences to meaningful discoveries. Cognition, 103, 180-226. doi:10.1037/a0024899

Hagberg, B., \& Gustafson, L. (1985). On diagnosis of dementia: Psychometric investigation and clinical psychiatric evaluation in relation to verified diagnosis. Archives of Gerontolology and Geriatrics, 4, 321-332. https://doi.org/10.1016/0167-4943(85)90039-1

Johansen, M. K., \& Osman, M. (2015). Coincidences: A fundamental consequence of rational cognition. New Ideas in Psychology, 39, 34-44.

https://doi.org/10.1016/j.newideapsych.2015.07.001

Johnson, C. (2015). Darwin's dice: The idea of chance in the thought of Charles Darwin. New York: Oxford University Press.

Jolfaee, S., Zazkis, R, R., \& Sinclair, N. (2014). “It is very, very random because it doesn't happen very often": Examining learners' discourse on randomness. In E. J. Cernoff \& B. Sriraman (eds.), Probabilistic thinking (pp. 397-416). Dordrecht, NL: Springer. DOI: 10.1007/978-94-007-7155-0_21

Jostmann, N. B., Lakens, D., \& Schubert, T. W. (2009). Weight as an embodiment of importance. Psychological Science, 20(9), 1169-1174. https://doi-

org.ezproxy.uio.no/10.1111/j.1467-9280.2009.02426.x 
Kadri, F., Birregah, B., \& Châtelelet, E. (2014). The impact of natural disasters on critical infrastructures: A domino effect-based study. Homeland Security \& Emergency Management, 11(2), 217-241. DOI 10.1515/jhsem-2012-0077

Kahneman, D. (2003). A perspective on judgment and choice: Mapping bounded rationality. American Psychologist, 58(9), 697-720. http://dx.doi.org.ezproxy.uio.no/10.1037/0003066X.58.9.697

Kahneman, D., Slovic, P., \& Tversky, A. (Eds.) (1982). Judgment under uncertainty: heuristics and biases. Cambridge, UK: Cambridge University Press.

Kahneman, D. \& Tversky, A. (1972). Subjective probability: A judgment of representativeness. Cognitive Psychology, 3, 430-454. https://doi.org/10.1016/0010$\underline{0285(72) 90016-3}$

Kahneman, D., \& Tversky, A. (1996). On the reality of cognitive illusions. Psychological Review, 103(3), 582-591. doi:10.1037/0033-295X.103.3.582

Keren, G., \& Teigen, K. H. (2001). The probability-outcome correspondence principle: A dispositional view of the interpretation of probability statements. Memory \& Cognition, 29, 1010-1021. https://doi.org/10.3758/BF03195763

Keren, G. \& Teigen, K. H. (2010). Decisions by coin toss: Inappropriate but fair. Judgment and Decision Making, 5, 83-101.

Krantz, D. L. (1998). Taming chance: Social science and everyday narratives. Psychological Inquiry, 9, 87-94. https://www-jstor-org.ezproxy.uio.no/stable/1449097

Krumboltz, J. (2009). The happenstance learning theory. Journal of Career Assessment, 17, 135-154. doi: 10.1177/1069072708328861

Kupor, D., \& Laurin, K. (2019). Probable cause: the influence of prior probabilities on forecasts and perceptions of magnitude. Journal of Consumer Research, https://doi.org/10.1093/jcr/ucz025

Langley, J. D. (1988). The need to discontinue the use of the term "accident" when referring to unintentional injury events. Accident Analysis and Prevention, 20, 1-8.

https://doi.org/10.1016/0001-4575(88)90009-7

LeBoeuf, R. A., \& Norton, M. I. (2012). Consequence-cause matching: Looking to the consequences of events to infer their causes. Journal of Consumer Research, 39(1), 128-141. doi:10.1086/662372

Loimer, H., \& Guarnieri, M. (1996) Accidents and acts of God: A history of the terms. American Journal of Public Health, 86, 101-107.

Lucretius, T. C. (2015). The nature of things (trans. A. E. Stallings). Original work: De rerum naturae. London: Penguin Classics.

Malkiel, B. G. (2003). A random walk down wall street. New York: Norton

Mill, J. S. (1856). A system of logic. London: Parker. 
Nickerson, R. S. (2002). The production and perception of randomness. Psychological Review, 109(2), 330-357. doi: 10.1037//0033-295X.109.2.330

Nisbett, R., \& Ross, L. (1980). Human inference: strategies and shortcomings of social judgement. Englewood Cliffs, NJ: Prentice-Hall.

Nowicki, S., \& Strickland, B. R. (1973). A locus of control scale for children. Journal of Consulting and Clinical Psychology, 40, 148-154.

Oestreicher, C. (2007). A history of chaos theory. Dialogues in Clinical Neuroscience, 9(3), 279-289.

Osgood, C. E., Suci, G., \& Tannenbaum, P. (1967). The measurement of meaning.

Champaign: University of Illinois Press.

Oskarsson, A.T., Van Boven. L., McClelland, G. H., \& Hastie, R. (2009). What's next? Judging sequences of binary events. Psychological Bulletin, 135, 262-285.

Piaget, J., \& Inhelder, B. (1975). The origin of the idea of chance in children (trans. L. Leake Jr., P. Burrel, \& H. D. Fishbein). New York: Norton. (Original work published in 1951).

Poincaré, H. (1963). Chance. In H. Poincaré, Mathematics and science: last essays (trans. J. Bolduc). New York: Dover.

Pollatsek, A., \& Konold, C. (1991). Randomness is well enough understood to be misunderstood. Journal of Behavioral Decision Making, 4, 218-220.

Pratt, D. (1998). The co-ordination of meanings for randomness. For the Learning of Mathematics, 18(3), 2-11. https://www.jstor.org/stable/40248272

Pratt, D., \& Noss, R. (2002). The microevolution of mathematical knowledge: The case of randomness. The Journal of the Learning Sciences, 11(4), 455-488.

https://doi.org/10.1207/S15327809JLS1104_2

Pritchard, D., \& Smith, M. (2004). The psychology and philosophy of luck. New Ideas in Psychology, 22, 1-28. https://doi.org/10.1016/j.newideapsych.2004.03.001

Rosset, E. (2008). It's no accident: Our bias for intentional explanations. Cognition, 108, 771780. https://doi.org/10.1016/j.cognition.2008.07.001

Rotter, J. B. (1966). Generalized expectancies for internal versus external control of reinforcement. Psychological Monographs, 80 (Whole No. 609).

Ruvinsky, A. (2010). Genetics and randomness. Boca Raton, FL: Taylor \& Francis.

Salomone, P. R., \& Slaney, R. B. (1981). The influence of chance and contingency factors on the vocational choice process of nonprofessional workers. Journal of Vocational Behavior, 19, 25-35. https://doi.org/10.1016/0001-8791(81)90046-4

Sapir, E. (1929). A study in phonetic symbolism. Journal of Experimental Psychology, 12, 225-239. doi:10.1037/h0070931 
Scholl, S. G., \& Greifeneder, R. (2011). Disentangling the effects of alternation rate and maximum run length on judgments of randomness. Judgment and Decision Making, 6, 531541.

Shanahan, M. J., \& Porfeli, E. J. (2006). Chance events in the life course. Advances in Life Course Research, 11, 97-119. https://doi.org/10.1016/S1040-2608(06)11004-7

Sunstein, C. R. (2015). How Star Wars illuminates constitutional law. Michigan Law Review, http://nrs.harvard.edu/urn-3:HUL.InstRepos:16148344

Taleb, N. N. (2007). The black swan: The impact of the highly improbable. New York: Random House.

Teigen, K. H. (1995). How good is good luck? The role of counterfactual thinking in the perception of lucky and unlucky events. European Journal of Social Psychology, 25, 281302. https://doi.org/10.1002/(SICI)1099-0992(199912)29:8<981::AID-EJSP966>3.0.CO;2-Z

Teigen, K. H. (2005). When a small difference makes a big difference: Counterfactual thinking and luck. In D. R. Mandel, D. J. Hilton \& P. Catellani (Eds.), The psychology of counterfactual thinking (pp.129-146). London: Routledge.

Teigen, K. H. (2017). Judgments by representativeness. In R. F. Pohl (Ed.). Cognitive illusions: Intriguing phenomena in thinking, judgment, and memory (2nd ed.) (pp. 204-222). London and New York: Psychology Press.

Teigen, K. H., \& Keren, G. (2019). Must random events be rare? On the relationship between perceived randomness and outcome probability. Paper under review.

Tervo, D. G. R., Proskurin, M., Manakov, M., Kabra, M., Vollmer, A., Branson, K., \& Karpova, A. Y. (2014). Behavior variability through stochastic choice and its gating by anterior cingulate cortex. Cell, 159(1), 21-34. https://doi.org/10.1016/j.cell.2014.08.037

Tversky, A., \& Kahneman, D. (1982). Judgments of and by representativeness. In D. Kahneman, P. Slovic, \& A. Tversky (Eds.), Judgment under uncertainty: Heuristics and biases (pp. 84-98). Cambridge: Cambridge University Press.

Yu, R. Q., Gunn, J., Osherson, D., \& Zhao, J. (2018). The consistency of the subjective concept of randomness. Quarterly Journal of Experimental Psychology, 71(4), 906-916. https://doi.org/10.1080/17470218.2017.1307428

Williams, E. N., Soeprapto, E., Like, K., Touradji, P., Hess, S., \& Hill, C. E. (1998). Perceptions of serendipity: Career paths of prominent academic women in counselling psychology. Journal of Counseling Psychology, 45, 379-389. doi:10.1037/00220167.45.4.379

Wikipedia (n.d). Random walk hypothesis. https://en.wikipedia.org/wiki/Random_walk_hypothesis 
Table 1. Preference (percentages) for small vs. large effects as due to chance, Experiment 1

\begin{tabular}{|c|c|c|c|}
\hline & $\begin{array}{l}\text { Statements about small vs. large effects as due to chance, } \\
\text { Version } a \text {. [Version } b \text { in brackets] }\end{array}$ & $\begin{array}{l}\text { Favoring } \\
\text { small }\end{array}$ & Binomial $p$ \\
\hline Q1 & $\begin{array}{l}\text { Eric came very close to / was very far from winning the } \\
\text { competition. Pure chance kept him from winning [By } \\
\text { accident, he did not win]. }\end{array}$ & $90.5 \%$ & $<.001$ \\
\hline $\mathrm{Q} 2 *$ & $\begin{array}{l}\text { Hannah did not win accidentally [by chance]. She won by a } \\
\text { large / small margin. }\end{array}$ & $82.9 \%$ & $<.001$ \\
\hline Q3 & $\begin{array}{l}\text { Bob produced the wrong answer to a math problem } \\
\text { because he accidentally made [happened to make] a small / } \\
\text { huge mistake. }\end{array}$ & $87.4 \%$ & $<.001$ \\
\hline Q4 & $\begin{array}{l}\text { Beth obtained good grades throughout the year. On her } \\
\text { final exam, she happened to perform [she accidentally } \\
\text { performed] slightly worse / much worse than she used to. }\end{array}$ & $66.3 \%$ & $<.001$ \\
\hline Q5* & $\begin{array}{l}\text { The CEO did not just happen to get an extremely large / a } \\
\text { small bonus [did not get it just by chance]. }\end{array}$ & $76.9 \%$ & $<.001$ \\
\hline Q6* & $\begin{array}{l}\text { It was no accident that the company's revenue had } \\
\text { increased by } 50 \% / 5 \% \text {. [This did not happen by chance]. }\end{array}$ & $78.9 \%$ & $<.001$ \\
\hline Q7 & $\begin{array}{l}\text { It was purely accidental that [Incidentally] the Sparrows } \\
\text { climbed one place / five places on the soccer table. }\end{array}$ & $65.3 \%$ & $<.001$ \\
\hline Q8 & $\begin{array}{l}\text { Jane was incidentally [accidentally] } 5 \text { minutes / } 60 \text { minutes } \\
\text { late for the appointment. }\end{array}$ & $88.9 \%$ & $<.001$ \\
\hline Q9 & $\begin{array}{l}\text { Small and harmless / large and dangerous landslides occur } \\
\text { quite randomly [can be described as chance occurrences]. }\end{array}$ & $44.7 \%$ & Ns \\
\hline Q10 & $\begin{array}{l}\text { A small / large explosion that left two people slightly } \\
\text { injured / killed } 50 \text { people happened purely by chance [was } \\
\text { a random occurrence]. }\end{array}$ & $62.3 \%$ & $<.01$ \\
\hline Q11 & $\begin{array}{l}\text { The argument arose by pure chance [by accident]. It was } \\
\text { due to a minor disagreement / a major conflict between the } \\
\text { parties. }\end{array}$ & $86.9 \%$ & $<.001$ \\
\hline Q12 & $\begin{array}{l}\text { The malfunction was a random occurrence [was due to } \\
\text { chance]. It was quite inconsequential / quite serious. }\end{array}$ & $48.2 \%$ & Ns \\
\hline
\end{tabular}

* Reverse framed 
Table 2. Mean preference scores (1-5), Experiment 2. Lower scores indicate more agreement with alternatives written in bold

\begin{tabular}{|c|c|c|c|c|c|}
\hline \multirow{2}{*}{$\begin{array}{l}\text { Item } \\
\text { no. }\end{array}$} & \multirow{2}{*}{$\begin{array}{l}\text { Statement pairs, small condition [large condition } \\
\text { in brackets] }\end{array}$} & \multicolumn{2}{|c|}{ Condition } & \multirow[b]{2}{*}{$t$} & \multirow[b]{2}{*}{$P$} \\
\hline & & Small & large & & \\
\hline$\# 1$ & $\begin{array}{l}\text { Minor [major] road accidents are } \\
\text { often due to / almost never due to chance }\end{array}$ & 2.74 & 3.05 & 1.68 & .096 \\
\hline $\begin{array}{l}\# 2 \\
\text { (filler) }\end{array}$ & $\begin{array}{l}\text { A small [large] increase in temperature will have } \\
\text { small effects / large effects on plant life in the } \\
\text { region }\end{array}$ & 3.76 & 4.19 & 2.69 & .008 \\
\hline \#3 & $\begin{array}{l}\text { A small [big] win in blackjack is } \\
\text { often / rarely determined by chance alone }\end{array}$ & 1.99 & 2.43 & 2.48 & .014 \\
\hline $\begin{array}{l}\# 4 \\
\text { (filler) }\end{array}$ & $\begin{array}{l}\text { A small [large] change in foreign policy may have } \\
\text { small / large effects on our relationship with our } \\
\text { allies }\end{array}$ & 3.85 & 3.98 & .76 & .447 \\
\hline \#5 & $\begin{array}{l}\text { Chance had } \\
\text { a lot / nothing to do with the fact that Steve lost } \\
\text { some of his money [all his money] }\end{array}$ & 3.03 & 3.37 & 1.90 & .059 \\
\hline $\begin{array}{l}\# 6 \\
\text { (filler) }\end{array}$ & $\begin{array}{l}\text { A small [large] mistake will have } \\
\text { an insignificant / a significant effect on the } \\
\text { company's reputation }\end{array}$ & 3.35 & 4.06 & 3.85 & $<.001$ \\
\hline \#7 & $\begin{array}{l}\text { Throughout adulthood, small [large] variations in } \\
\text { life satisfaction are } \\
\text { often / rarely due to random occurrences }\end{array}$ & 2.44 & 2.89 & 2.44 & .016 \\
\hline \#8 & $\begin{array}{l}\text { It was } \\
\text { due to chance / not due to chance that Paul got } \\
\text { slightly [seriously] ill on his last vacation }\end{array}$ & 2.41 & 2.66 & 1.34 & .18 \\
\hline $\begin{array}{l}\text { Mean } \\
\text { random }\end{array}$ & Items $1,3,57,8$ & 2.52 & 2.88 & 3.66 & $<.001$ \\
\hline $\begin{array}{l}\text { Mean } \\
\text { fillers }\end{array}$ & Items 2, 4, 6 & 3.65 & 4.08 & 3.53 & $<.01$ \\
\hline
\end{tabular}

Note: Filler items described small and large effects as a result of small (large) causes, without mentioning randomness or chance. 
Table 3. Number of participants selecting and providing different types of stories illustrating chance in life, Experiment 3

\begin{tabular}{|c|c|c|c|c|c|}
\hline & \multirow[t]{2}{*}{$\begin{array}{l}\text { Expected content in stories } \\
\text { about chance events }\end{array}$} & \multicolumn{2}{|c|}{$\begin{array}{l}\text { Respondents with } \\
\text { stories }\end{array}$} & \multirow{2}{*}{$\begin{array}{l}\text { Respondents } \\
\text { without } \\
\text { stories }\end{array}$} & \multirow[t]{2}{*}{$\begin{array}{l}\text { All } \\
\text { respondents }\end{array}$} \\
\hline & & Real & Made up & & \\
\hline 1. & $\begin{array}{l}\text { large things that are not } \\
\text { very consequential }\end{array}$ & 2 & 1 & 3 & 6 \\
\hline 2. & $\begin{array}{l}\text { large things that can be } \\
\text { very consequential }\end{array}$ & 1 & 0 & 2 & 3 \\
\hline 3. & $\begin{array}{l}\text { small things that are not } \\
\text { very consequential }\end{array}$ & 11 & 1 & 6 & 18 \\
\hline \multirow[t]{2}{*}{4.} & $\begin{array}{l}\text { small things that can be } \\
\text { very consequential }\end{array}$ & 17 & 13 & 38 & 68 \\
\hline & Sum & 31 & 15 & 49 & 95 \\
\hline
\end{tabular}




\section{Figure captions}

Fig. 1. Random walk of fictitious stock (based on the odd/even values of the decimals of $\pi$ ), condensed version (upper panel) and accentuated version (lower panel) used in Condtion 1 and 2, Experiment 4. Graphs adapted from Wikipedia (n.d).

Fig. 2. Percentages of participants perceiving changes in stock prices as nonrandom, arranged according to magnitude of change from large to small (change \#18 and \#38 were of equal magnitude, change \#7 and \#19 were also equal).

Fig. 3. Mean randomness ratings for amount and ability of five small vs. five large wingedcreatures (left panel) and five small vs. large four-legged animals (right panel), Experiment 5 a.

Fig. 4. Percentages of respondents suggesting that a species of eel moving along a random or regular trajectory must be smaller / larger than other eels, Experiment $5 \mathrm{~b}$. 


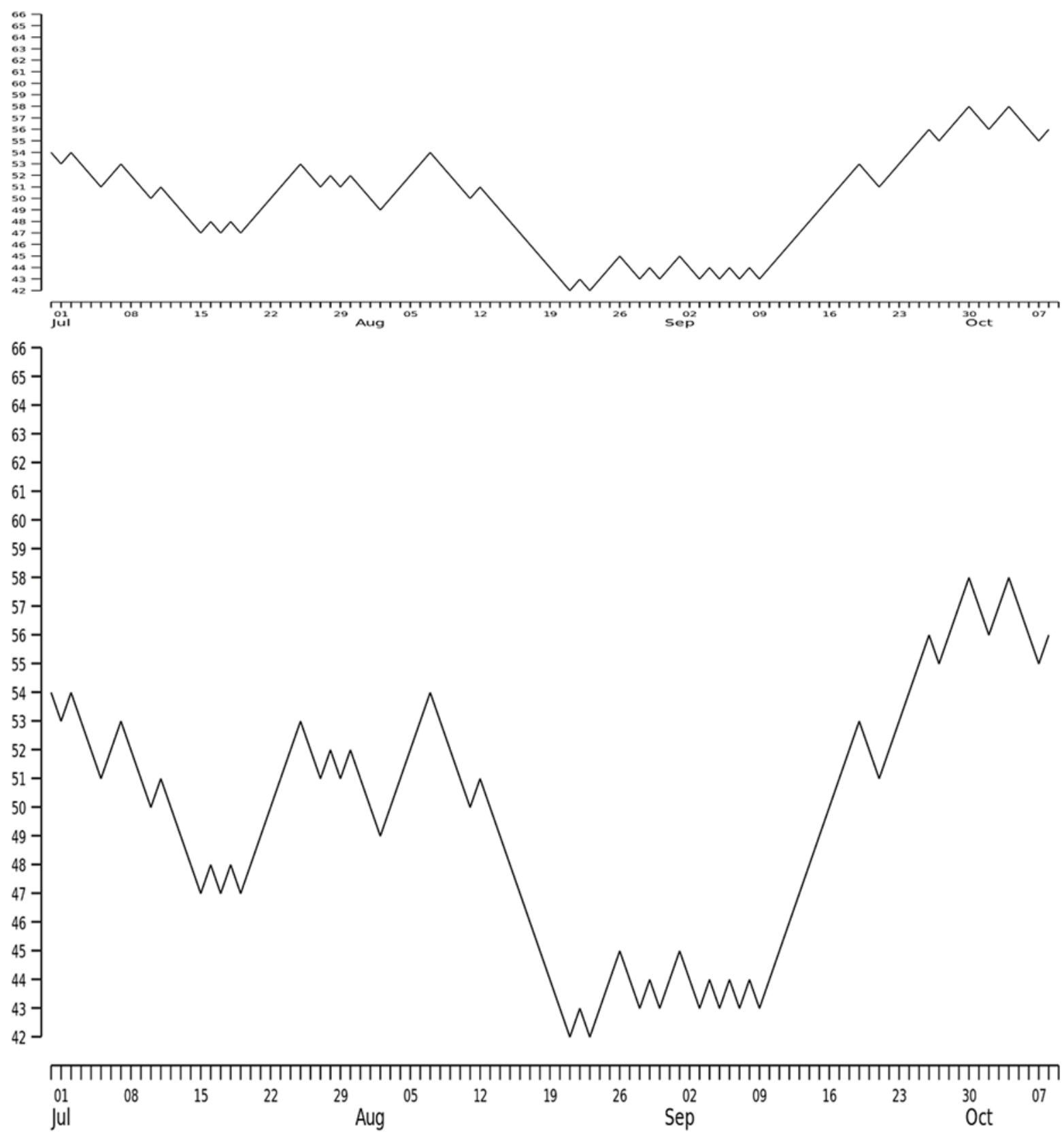

Fig. 1. Random walk of fictitious stock (based on the odd/even values of the decimals of $\pi$ ), condensed version (upper panel) and accentuated version (lower panel) used in Condtion 1 and 2, Experiment 4. Graphs adapted from Wikipedia (n.d). 


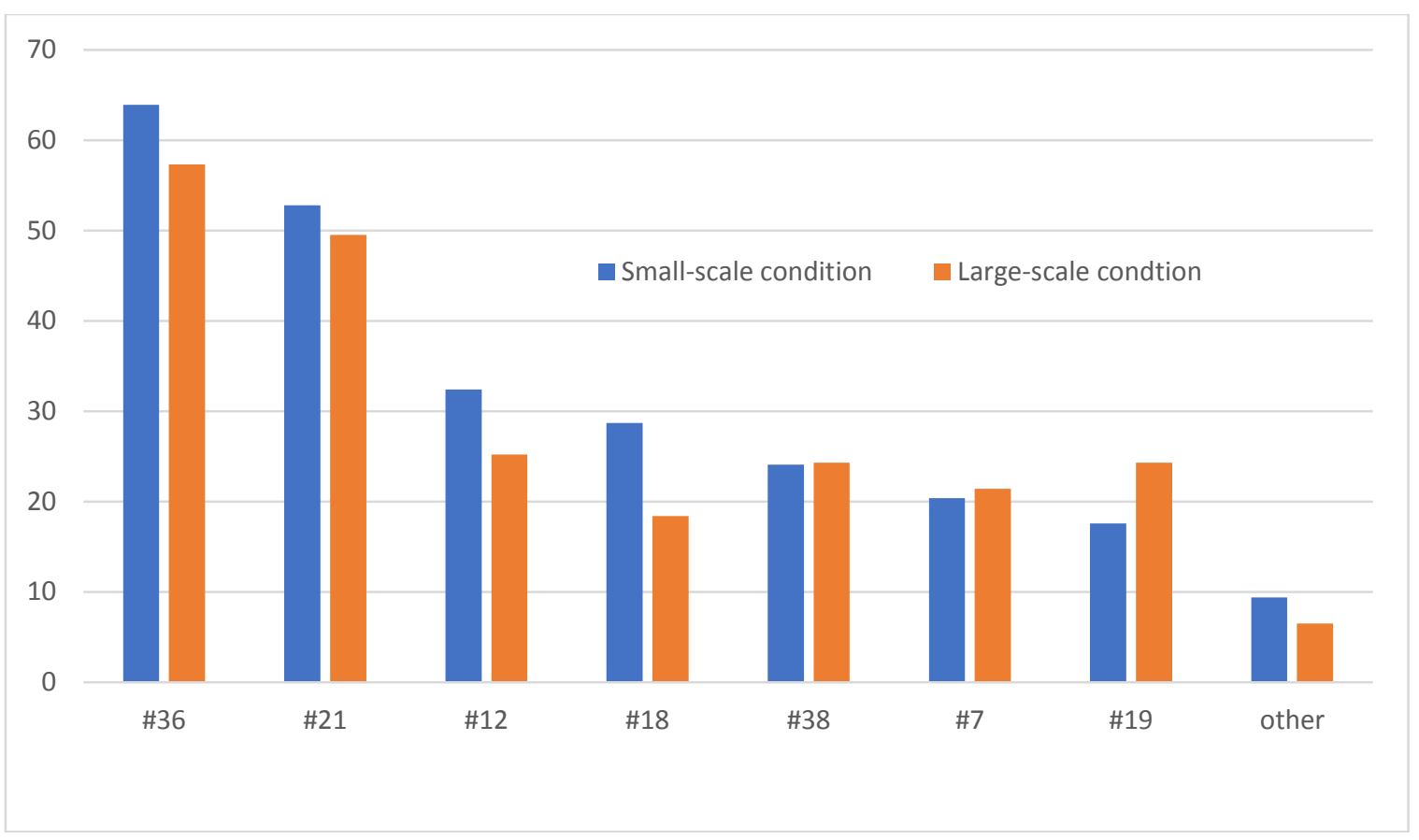

Fig. 2. Percentages of participants perceiving changes in stock prices as nonrandom, arranged according to magnitude of change from large to small (change \#18 and \#38 were of equal magnitude, change \#7 and \#19 were also equal). 


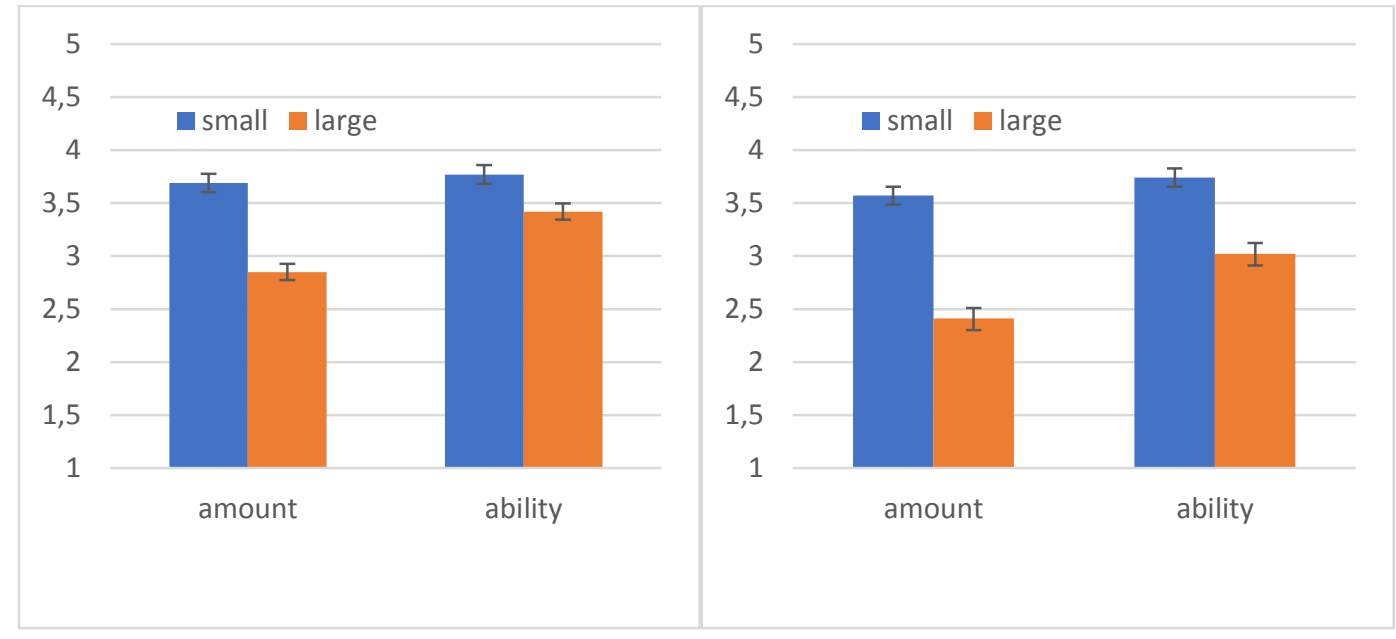

Fig. 3. Mean randomness ratings for amount and ability of five small vs. five large wingedcreatures (left panel) and five small vs. large four-legged animals (right panel), Experiment 5a. (Error bars represent \pm SEM.) 


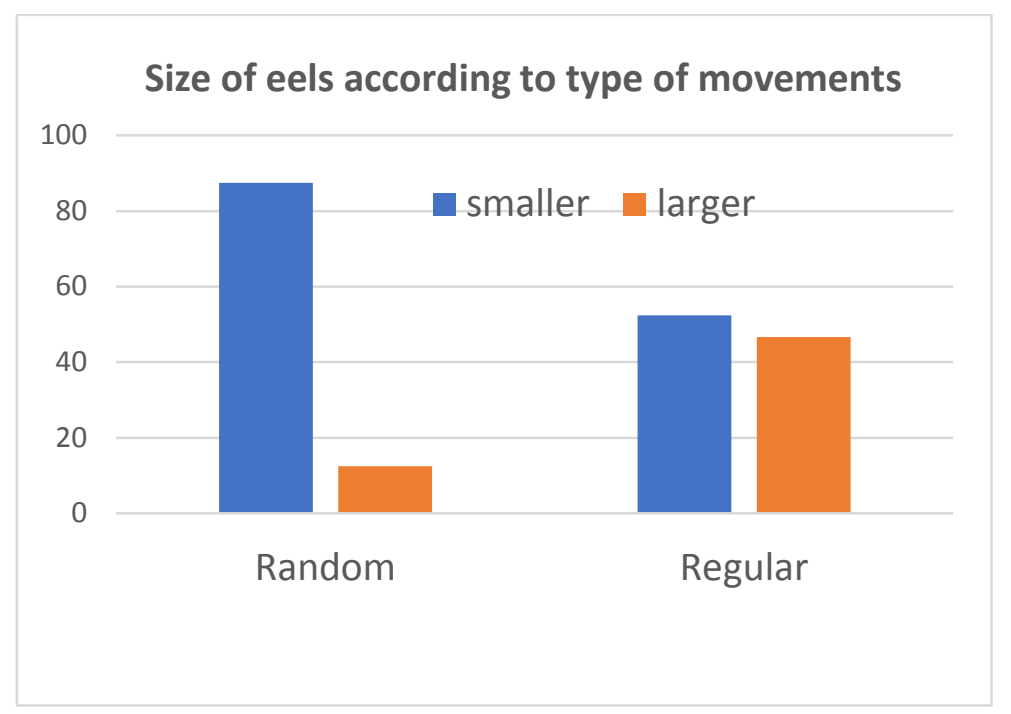

Fig. 4. Percentages of respondents suggesting that a species of eel moving along a random or regular trajectory must be smaller / larger than other eels, Experiment $5 b$. 


\section{Appendix}

Approximate weights based on various internet sources (e.g., Wikipedia).

Insects and birds:

Mosquito

$2.5 \mathrm{mg}$

Bee

$113.3 \mathrm{mg}$

Hummingbird

$3.6 \mathrm{~g}$

Sparrow

$32.5 \mathrm{~g}$

Parakeet

$35 \mathrm{~g}$

Magpie

$177.5 \mathrm{~g}$

Crow

$450 \mathrm{~g}$

Eagle

$4.4 \mathrm{~kg}$

Pelican

$7 \mathrm{~kg}$

Swan

$10.3 \mathrm{~kg}$

Mammals:

House mouse

$42.5 \mathrm{~g}$

Brown Rat

$320 \mathrm{~g}$

Guinea pig

$950 \mathrm{~g}$

Rabbit

$1.2 \mathrm{~kg}$

Domestic cat

$4.5 \mathrm{~kg}$

Siberian tiger

$147.2 \mathrm{~kg}$

Pony

$192.8 \mathrm{~kg}$

Arabian horse

$405 \mathrm{~kg}$

Hippo

$1400 \mathrm{~kg}$

Indian elephant

$3500 \mathrm{~kg}$ 


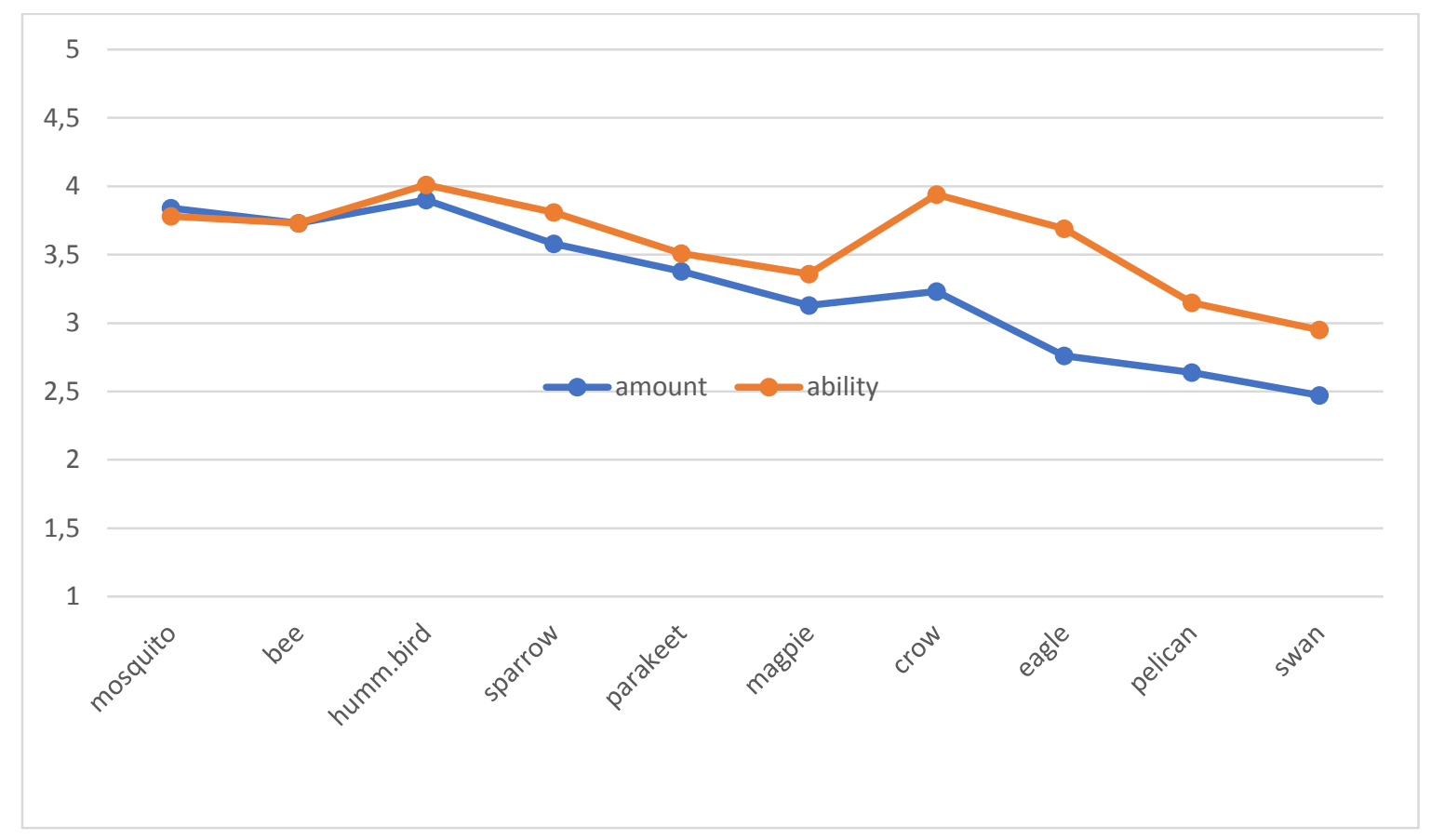

Fig. 5. Mean ratings of amount and ability for randomness of insects and birds, ordered according to size

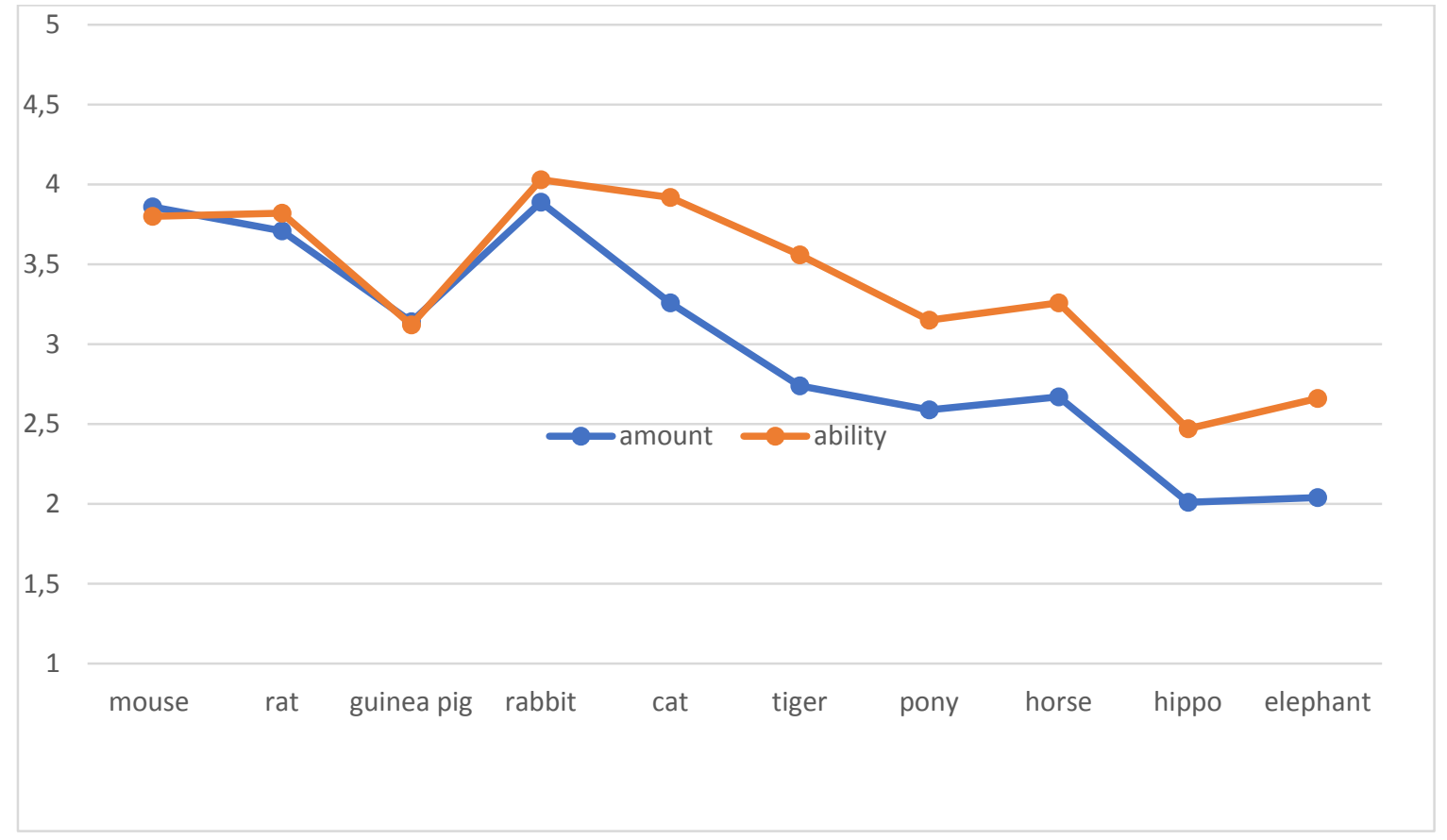

Fig. 6. Mean ratings of amount and ability of randomness for mammals, ordered according to size 